\title{
Health concerns of young Israelis moving from the ultra-orthodox to the secular community: vulnerabilities associated with transition
}

\author{
Baruch Velan, ${ }^{1}$ Ronit Pinchas-Mizrachi ${ }^{2}$ \\ ${ }^{1}$ The Gertner Institute for Epidemiology and Health Policy Research, Sheba Medical Center; ${ }^{2}$ Ramat Gan Academic College, Ramat \\ Gan, Israel
}

\begin{abstract}
Many young Israelis leave the Ultra-Orthodox religious community to join the secular world. In this study we examine health considerations of ex-Orthodox (ExOr) individuals in an attempt to define their vulnerabilities and needs.12 young adults were asked to relate to health problems that trouble the ExOr community. The semi-structured interviews were analyzed qualitatively to identify relevant motives. Interviewees indicated that the ExOr population could be affected by mental health problems, including stress and depression, by sexual health problems, and by risks related to substance abuse and hazardous behavior. Interviewees suggested that these problems are associated with difficulties encountered prior and during the transition process, as well as with the hardships of acculturation and assimilation in the secular world. Comparisons to previous findings on the health of immigrants, young adults and LGBT populations suggest that the process of transition per-se could engender vulnerability and trigger health problems.
\end{abstract}

\section{Introduction}

Considerable attention has been given, in recent years, to the health of specific sub-populations. This has been

\begin{abstract}
Correspondence: Baruch Velan, The Gertner Institute for Epidemiology and Health Policy Research, Sheba Medical Center, 1 Emek Dotan Str. Ramat Gan 5262100, Israel.

Tel.: +972546725057.

E-mail: baruch_v@yahoo.com

Acknowledgements: the authors would like to thank the out for change organization for their assistance with this study, and especially Mr. Yosi Klar for introducing them to the ex-Orthodox community and helping them understand the needs. The authors also tank Prof. Yaacov Yadgar for sharing with them his insights on religiosity in Israel.
\end{abstract}

Key words: Mental health; Sexual health; Substance abuse; Risky behavior; Vulnerable population; Immigrant's health; LGBT health; Religion.

Contributions: the authors contributed equally.

Conflict of interest: the authors declare no potential conflict of interest.

Funding: funding was provided through the research budget of the Israel Academic College.

Received for publication: 24 January 2019.

Revision received: 19 March 2019

Accepted for publication: 19 March 2019.

This work is licensed under a Creative Commons Attribution NonCommercial 4.0 License (CC BY-NC 4.0).

CCopyright B. Velan and R. Pinchas-Mizrachi, 2019

Licensee PAGEPress, Italy

Qualitative Research in Medicine \& Healthcare 2019; 3:32-39

doi:10.4081/qrmh.2019.8051 guided by the understanding that certain populations may have specific predispositions to illnesses, or may encounter specific barriers in access to healthcare. ${ }^{1-3}$

The dimensions of population vulnerability are numerous and could be associated with variables as low income, ${ }^{4}$ age, ${ }^{5}$ gender $^{6}$ and social status. ${ }^{7}$ Many national health programs relate to the special health requirements of older people, racial and ethnic minorities and people with disabilities. In Israel, special attempts have been made, over the years, to examine the health needs of various subpopulations, including Arabs, ${ }^{8}$ Ultra-Orthodox Jews, ${ }^{9}$ and immigrants from the former Soviet Union ${ }^{10}$ or from Ethiopia. ${ }^{11}$

Understanding the needs of identified vulnerabilitypopulations is crucial to addressing their problems through appropriate health policies. In addition, health authorities should also be sure that all potential groups at risk are indeed identified.

Here we draw attention to the health of a specific group in the Israeli population, namely that of young people who have left the ultra-Orthodox religious community to join the main stream non-religious community. ${ }^{12}$ These individuals, often referred to as Ex-Orthodox (ExOr) or answer seekers, are gaining volume both in number and visibility, and reflect ongoing social and demographic changes in the Israeli society. ${ }^{13}$ More and more young individuals who spent their formative years in an extremely religious environment choose, as young adults, to make the transition to the secular world. Similar trends have been observed among ultra-Orthodox Jewish communities outside of Israel, ${ }^{14,15}$ as well as among highly religious Christian communities. ${ }^{16,17}$

Leaving the ultra-Orthodox world involves notable challenges. Those who leave are often banished from family and other support groups. Many of them face isolation, financial distress and struggle with gaps in basic educa- 
tion, and preparedness for employment. ${ }^{12,14}$ These hardships can easily translate to social vulnerability and eventually affect the health of ExOr. All this can be potentiated by the fact that transition to secularity occurs most often during young adulthood, an age noted for its specific health vulnerabilities. ${ }^{18}$

Moving from the Orthodox world to the secular one is a complex process. It is marked by a formal act of abandoning characteristic religious practices, such as wearing head covers or observing the Shabbat. It should be noted however that this formal step is preceded by a long period of deliberation, and is then followed by a long period of cultural adaptation..$^{13,19}$

This transition process resembles two other transition processes: immigration from one country to another and coming out for LGBT persons. Both processes resemble secularization as they involve the decisive formal step, preceded by deliberations, and followed by acculturation. In the case of immigrants, like in the case of ExOr, financial, bio-medical, structural and cognitive factors can potentially contribute to health vulnerability. ${ }^{20}$ In the case of LGBT people, like in the case of ExOr, individuals struggle with an identity crisis, doubts, disguise and stigmatization $^{21,22}$ which can have a toll on health.

This is an exploratory study, in which we interviewed 12 young adults who have recently made the transition from the Jewish Orthodox world to the secular world. We asked them to identify prevalent health problems among ExOr, and then used their accounts to portray the health vulnerabilities of this emerging population.

\section{Materials and Methods}

\section{Study sample}

We initially recruited interviewees through the mailing list of Out for Change (Yozimleshinuy), a nonprofit organization assisting ExOr individuals in their new life. Later on recruitment continued through what is known as snowballing, where interviewees recruited other people for the study.

In the end, we interviewed twelve young adults, who identified themselves as ex Orthodox Jews who had recently transitioned to the secular society. We ended recruitment after the $12^{\text {th }}$ interview, once a preliminary content analysis revealed that we had reached a point of repetition in the data.

The study sample included 8 males, 22-34 years old, and 4 females, 20-29 years old. All participants were brought up in Orthodox Ashkenazi Jewish families (ancestors originating from Europe) identified as Hasidic or Non-Hasidic (the two major branches of Jewish Orthodoxy). Eight of the participants were single, one married and 3 divorced (males who left behind their spouses and children during the process of secularization)

Overall, the process of secularization was rather long for the participants. The beginning of the process occurred between the ages of 15-22, with a median age of 18 . The formal step of coming out, namely the act of abandoning religious practices and informing others about the change in identity, occurred between the ages of 16-29, with a median age of 21 . The interviews were conducted 2-5 years after coming out in the case of 6 interviewees, and 6-13 years after coming out in the case of the other six.

\section{Interviews}

We conducted interviews in Hebrew using a semistructured format that was designed by us. Each lasted between 50 and 100 minutes.

Interviews included the following steps:

i) The interviewees were informed about the aims of the study, the format of the interview, and the identity and affiliations of the researchers. At this stage, full anonymity was assured.

ii) The interviewees were asked to respond to a single open-ended question: What in your opinion are the health concerns of ExOr? All statements were recorded, without any interference or guidance.

iii) The same question was asked again, after indicating that health does not necessarily mean bodily heath, and can include wider aspects of health, and again all statements were recorded, without any interference or guidance.

iv) Interviewees were asked to address special concerns about mental health, sexual health, safe behavior and healthy lifestyle.

\section{Content analysis}

We used a content analysis in order to identify what we defined as major motives in the interviews. We designed our content analysis methodology by drawing from an interpretative phenomenological approach. ${ }^{23}$ Interpretative phenomenological analysis (IPA) focuses on examining personal lived experiences. It entails detailed analysis of personal accounts, and examination of how individuals make meaning of their life experiences. This is paired with the interpretations of the researchers to create a double hermeneutics, or a lamination of interpretative positioning. In contrast to grounded theory, another widely used qualitative methodology, IPA does not focus on generating a theory for the process, but rather on describing and interpreting the essence of the process.

In this specific study interviewees provided information on health concerns among ExOr, together with personal accounts on the experiences of leaving the Orthodox world. Based on their own accounts, interviewees were encouraged to propose interpretations on possible interrelationships between emerging health problems and the process of moving out. Authors then used these proposed interpretations to build higher level insights on the health vulnerabilities of populations in transition. 
The transcript of each interview was screened for coherent statements, yielding lists of 30-50 statements per interview. We then examined each list and typified the statements into categories by using three criteria: i) identification of a health related motives (e.g. mental health, sexual health, risky behavior), ii) identification of societal motives (e.g. isolation, deprivation, loss of boundaries, iii) reported association with the act of transitioning (e.g. causative association, indirect association, lack of association). This typification was conducted separately by each of the researchers, and notes were then compared. In most cases typification was similar; differences were resolved by mutual agreement. The list of identified motives was used to extract the most relevant quotation, to be included in the Result section, using the medical typology as lead, and the two other typologies as a means for interpretation. In parallel annotation was conducted by processing the texts with the Atlas.ti software system. This analysis did not provide additional significant motives.

We should note that one of the authors was brought up in an Orthodox family, conducts a moderate Orthodox lifestyle, and is personally acquainted with ExOr individuals. The other author adheres, in practice and ideology to secular Judaism. Both authors made their best to be impartial and objective, and to refrain from any sort of partisanism. Nevertheless, the authors did exercise a certain form of censorship, as quotations that risked compromising the interviewees (loss of anonymity, abuse experiences, highly intimate information, conflict with the law) were not included.

\section{Results}

\section{Health related concerns of Orthodox religious individuals turning secular}

The act of leaving the Orthodox society occurs most often between the ages of 18-26. At this age most people feel that they are at the prime of their health, and are not expected to be concerned about medical problems. Nevertheless this did not seem to be the case for many of the young ExOr interviewed in this study.

Except for two interviewees who claimed that no specific health problems can be associated with ExOr, all others were quick to comment on medical concerns that bother ExOr. Moreover, there was a consensus among these 10 interviewees that the major concerns of ExOr relate to mental health. This was manifested by the striking similarities in their statements:

The first and most significant problem is mental health. Their problems relate to the health of the mind, stress, anxiety and such.

ExOr should be regarded as a group with specific mental health problems. They all need a major 'makeover' in this domain.
Mental health problems are of major concern among ExOr; this is critical and should be taken care of.

In addition, several interviewees have described concerns related to sexual health and to risky behavior: There are all those things that people don't talk about. Everything that relates to sex is a problem. and ExOr may have drinking problems, drug problems and engage in dangerous sexual practices.

Physical or direct bodily medical problems were not associated with leaving the orthodox world, yet some interviewees related to poverty, and to the difficult life conditions associated with transition that can indirectly affect physical health: ExOr often don't have the money to access the best health care, they are more susceptible to illness, as they their struggles lead to exhaustion, fatigue, and wearing down.

All the information provided above relates to answers to the general question about health concerns, asked in the first part of the interviews. Taken together, these spontaneous responses revealed that the major concerns of ExOr related to mental health, sexual health and risky behavior. Problems of this nature are not uncommon among young adults in many different societies. Therefore, their association with the act of secularization required further examination. To this end, participants were asked to speak further about each of the above mentioned health problems, to provide more information, and to explain their perceptions of the possible association between these specific problems and the experience of leaving the Orthodox world. All this is detailed in the following sections.

\section{Prevalence of mental health problems among Ex-Orthodox}

Analysis of all interviews suggests that ExOr are preoccupied by mental health. This is manifested by the fact that all interviewees, even those denying health concerns in the first round of questions, eventually indicated that mental health problems are prevalent among ExOr. Moreover, examination of the interview transcripts revealed that the major part (volume wise) of many conversations was dedicated to these issues. This impression was further substantiated by the fact that 5 of the 12 interviewees attested to personal experiences related to mental health problems.

Various manifestations of depression appear to be quite prevalent among ExOr as indicated by accounts of first hand experiences: After coming out, I felt grounded. I did not work for an entire year. I was not able to do anything. Another interviewee described a similar experience: I had this strange feeling, I don't know if this was depression, but I did not feel like getting out of bed, or meeting other people. Depression was also described as a second hand experience: Many of the people I know are undergoing psychological therapy. A close friend of mine exhibited symptoms of anxiety immediately after transitioning and needed treatment. Other descriptions included indication of lasting sleeplessness, anxiety and stress, as 
expressed by two interviewees: I came out two years ago and I still have sleeping problems or Today, I don't experience real anxiety, but still something inside me keeps me worried. I am working, I have a car, have a home, but there is always this feeling of uncertainty.

While being unanimous about the prevalence of certain mental health problems, interviewees did not feel that suicide can be defined as a specific risk for ExOr. In recent years, two cases of suicide among ExOr gained much publicity and attention, yet interviewees did not report on suicide attempts among their ExOr friends. One interviewee felt that there is a misconception about suicide among ExOr that is enhanced by popular media. This interviewee related to this in a very colorful way: Let's assume that someone speculates that redheads tend to kill themselves because they feel different. Then the media starts to report on every redhead that committed suicide, and this becomes an accepted notion.

\section{The association between mental health problems and moving out from the Orthodox world}

Each of the steps in the process of transition from the Orthodox to the secular world can be very strenuous emotionally. The years prior to formal transition are marked by spiritual struggles and by questions about faith, values and the right way of life. One interviewee described this as following: I struggled with God, struggled with my faith. At the end of the struggle I become a different person, but this had great emotional consequences. Religious and spiritual struggles can be very stressful and affect health. ${ }^{24}$ In the case of ExOr, this stress can be enhanced by the fact that the struggle usually occurs while young individuals attend religious schools, and hide their religious doubts from their peers.

The actual act of moving out or coming out is probably stressful as well. One reveals the change in the religious orientation to others, leaves home and school, and undergoes a transformation in appearance (no head cover, no beard, no modest constraining clothing). Moreover, the immediate outcome of this step is the loss of social support. ExOr transition from a much protected, familiar world to a terra incognita, where they feel vulnerable and disorientated: We leave a very organized, extremely protective environment to an environment where everything is new, where you don't have your own place. This is a difficult experience, very stressful. Another interviewee described this as following: We move from one form of anxiety, caused by living in a very intimate community, where everyone watches you, to another form of anxiety caused by being alone and deserted. The effect of isolation was expanded on by some interviewees: The Orthodox community is very protective, once you are out you feel deserted, No one is there to help you; My best friend deserted me, this broke my heart. As another interviewee said: There is nowhere to carry your pain.

The act of moving out is followed by a difficult period of acculturation. This was described as follows: We feel like immigrants in a new country. We look like the others, we talk like the others, but we are lost foreigners. The stress of adapting to the new country is often accompanied by stress caused by the harsh life conditions of most ExOr. They often encounter financial difficulties, and they need to find a place to live and seek education. Moreover, their religious education did not furnish them with skills required for earning a livening in a modern secular society. Some interviewees related to this; one provided the following description: At times, I maintained two jobs, at minimum wage, trying to save for school; I was exhausted.

While many indications suggest that the act of transition leads to mental health problems among ExOr, other perspectives were also proposed. Some interviewees argue that individuals who moved out the orthodoxy had a priori a pre-disposition for developing mental health problems. It is possible that a tendency of being contemplative and restless engender doubts in God as well as dissatisfaction with one's existence. One interviewee proposed the following evaluation: This is an egg and chicken situation, what came first? Did mental problems develop after moving out, or did individuals choose to move out because they carried some burden of mental problems. Another interviewee provided the following explanation: The transition is not an arbitrary event; it can be associated with specific personal traits. It is possible that those who are mentally fragile find it more difficult to remain in the Orthodox community.

While, as indicated above, most participants believed in some sort of linkage between mental problems and the transition process, two interviewees expressed a different approach. They claimed that the act of leaving the Orthodox community involves rebellion, courage and mental strength, and therefore, ExOr would be equipped with mental robustness: By definition, these guys should be mentally strong; they made a journey which requires great courage. ExOr that I know, are aware of their goals, and don't break down when encountering problems.

This perception that ExOr are equipped with intrinsic mental strength calls for optimism about the capability of ExOr to deal with their problems. It suggests that, with the appropriate help, ExOr will eventually overcome the problems inflicted by the transitional state. This was very nicely expressed by one the interviewees: I am taking care of myself, I am not hiding from my problems, I am coping with them. I talk about them. I am not afraid.

\section{Tendencies of Ex-Orthodox to engage in hazardous behavior}

Risky behavior is often associated with younger persons. Individuals in their late teens or early twenties can behave in ways that affect their health and even lead to fatalities. ${ }^{25}$ Therefore, it was not surprising to learn that ExOr often engage in activities that may jeopardize their health. This was expressed by interviewees in comments such as: 
Some ExOr live on the verge, they go to dangerous places, drive dangerously, do drugs and Some of us try everything: drugs, extreme activities, weird experiences.

It appears that drug use is common among some ExOr, yet, interestingly, excessive alcohol consumption was seldom mentioned as a risk factor for ExOr. When asked specifically, participants suggested that this, indeed, is not a common practice among ExOr. This may have some deeper roots related to attitude of Jewish people, in general, to drinking. ${ }^{26}$ On the other hand, ExOr appear to embark on dangerous trips: There is this practice of leaving for field trips in the desert without previous preparation, without taking enough water supplies. A popular destination for ExOr is the Sinai Peninsula, an Egyptian territory plagued by terrorist activities: All my friends often spend time in the Sinai Peninsula; they are not concerned about the ISIS threat.

It could be argued, rightfully, that dangerous behavior of ExOr could be attributed to the fact that most of them are in their early twenties, an age where individuals of all sectors may be prone to dangerous behavior. This was indeed expressed by one of the participants: Drug use is not necessarily specific to ExOr. All this is very individual; some will engage in a very normal lifestyle, others will act dangerously. The relative contribution of age $v s$ the transition process to engagement in dangerous practices among ExOr remains open. Nevertheless, interviewees suggested that the experience of moving out from the religious world bears some elements that enhance attraction to danger.

Some inherent characteristics of ExOr, such as curiosity, rebellion and willingness to break boundaries allowed them to make the transition from religiosity to secularity, and at the same time could enhance experimentation with drugs and extreme activities: These are 'searchers', they seek mind changing experiences, new excitements. In addition, the act of moving out harbors a feeling of newly acquired freedom, which can eventually lead to attempts to break additional boundaries: They feel that everything is open for them, no one can tell them what to do, they had enough of being told what to do.

Another motive relates to the use of drugs as a way of coping with the hardships of life after moving out the familiar religious community: They went through a major crisis, and are trying to recover through drugs and They need something, to ease their daily burdens; they want to be anesthetized.

In summary, dangerous conduct and substance abuse appear to be present in the lives of ExOr. This could be a simple manifestation of the fact that most of them belong to an age group that can be affected by such habits, or to the fact that they experience some sort of delayed adolescence. Nevertheless, the experience of moving out from the Orthodox society appears to enhance such practices.

\section{Difficulties in adopting healthy sexual practices}

Young individuals who leave the Orthodox society could be unprepared to deal with sexuality, as it is ex- pressed in the secular society. ${ }^{27}$ This could stem from the strict separation between males and females in the Orthodox society during childhood and adolescence, from gaps in sexual education, as well as from differences in the perceptions of sexuality by the Orthodox and secular communities. ${ }^{28}$ Sexual education is not part of Orthodox school curricula, and is provided only prior to marriage, focusing on its reproductive aspects. Thus young adults who leave Orthodoxy prior to getting married are often highly ignorant about sex, and those transiting after marriage have received a very one-sided education.

Another serious problem relates to the continuous emphasis on chastity and premarital abstinence in the Orthodox world. Sex is sometimes described as dirty and sinful, as expressed by one of the participants: Where I came from, sex was perceived as vulgar, animalistic. Talking about sex was not dignified, nor legitimate. This can lead to feelings of guilt related to experiencing natural sexual attraction: I was sure that I was a real pervert when I felt attraction to good-looking women. Moreover, certain Orthodox groups put high emphasis on prohibiting masturbation, and this is an additional source of frustration and stress: From the age of 13 they tell you, again and again, that masturbation will get you to hell. There is this book which describes the specific tortures that await those who have sinned by masturbation.

All these elements contribute to the mental health problems described above, and at the same time lead to major difficulties in sexual acculturation. These difficulties can be manifested in two ways: hazardous promiscuity on one hand, and refraining from sexual activity on the other hand.

The sudden freedom from sexual restriction can be very confusing. ExOr can be overwhelmed by the new sexual possibilities, and engage in very promiscuous practices: Once you left the religious environment, you feel that everything is permitted, no prohibitions, no restrictions. This could involve unsafe behavior and exposure to STIs: For some ExOr sex plays a dominant part in the transition process; they take part in orgies, practice unsafe sex, and catch sexually transmitted diseases.

A very serious aspect of this behavior could result in harming other people by misreading the unfamiliar sexual codes of the liberal society: They didn't know what was happening on the other side of the river, they don't understand the rules of conduct. This can have serious outcomes and even lead to harassment and sexual misconduct, directed by ExOr towards others: Some ExOr are confused about the signals that they get, and this can result in unintentional sexual harassment and assaults.

The encounter with the unfamiliar secular world can also lead to some sort of sexual impairment. Life in the Orthodox community can harm the ability to build healthy interactions with secular members of the opposite sex: Women are strange and forbidden creatures; they came from a different planet. ExOr can therefore reach adulthood 
with very limited sexual experience, and find it very difficult to overcome this gap: ExOr will be willing to learn many new things, but not when it comes to sex, they would rather run away. They cannot risk the shame of failure.

It should be noted that while many interviewees described difficulties in adopting healthy sexual practices, they also noted that with time, ExOr will find trustworthy partners and engage in satisfying relationships.

\section{Discussion}

Our content analysis of 12 interviews with young ExOr allowed us to identify the major health concerns of individuals that left the Orthodox world. These interviews enabled the interviewees to open up and disclose their attitudes and experiences in a way that most probably could not be achieved by other methodologies (our attempts to conduct focus groups discussions have failed to provide valuable information). Moreover, the analysis of the transcripts presented complexities that are difficult to achieve by non-quantitative methodologies.

Analysis of the interviews indicates that ExOr are affected by problems related to mental health, sexual health and risky behavior. Such problems are, obviously, not unique to the ExOr community. The qualitative nature of this study does not allow quantification of the prevalence of these problems among ExOr, and comparison to other populations. Nevertheless, careful content analysis of the interviews provides many indications that the process of transition from the Orthodox community to the secular society can trigger undesired effects on wellbeing and health. Moreover, analysis of our findings could point to a more generalized phenomenon, underscoring the possibility that the process of transition per-se could lead to the health vulnerabilities described here.

The secularization trajectory can be divided into three stages: the pre-transition stage, the transition stage and the post-transition stage. Each of these steps may have notable health impacts. Mental health problems can arise from the emotional struggles experienced prior to making the move, from the stress related to the transition itself, and from the anxieties associated with acquiring a new lifestyle. Problems related to sexual health can arise from the unpreparedness to sexual conduct in the secular world, as well as from the willingness to embrace the newly acquired sexual freedom. Substance abuse can be related to the desire to break all boundaries, but also to the hardship of dealing with daily life in an environment where family support was lost.

The transition process of ExOr brings to mind three other transition processes:

i) Immigration: The immigration trajectory resembles the secularization trajectory, and can also be divided into the pre-transition stage, the immigration stage and the post-immigration stage of resettlement. Each of these may have impacts on health. ii) Disclosure of sexual orientation for LGBT people: Coming out can also be divided into three phases: the pre-decision struggle, the act of the coming out, and finally the phase of adaptation. These steps are again very strenuous, and could have an effect on health.

iii) The natural process of growing up or more specifically moving from adolescence to adulthood is basically a transition process. This process is defined by a troublesome pre-transition state, namely adolescence, and the transition into young adulthood which can be stressful as well.

The major observation in this study is related to the mental health difficulties of ExOr. Similar difficulties were reported for immigrants, LGBT people and young adults. A large body of research has been dedicated to mental health problems of immigrants, which include panic attacks, sleeplessness, and depression, mood and anxiety disorders..$^{29}$ Moreover, like in the case of ExOr, the contributing factors to mental health problems among immigrants could include loss of one's social network, disruption of family ties, harsh living conditions, and difficulties in acculturation and adaptation. ${ }^{30,31}$

Opinions on suicide risk among immigrants are divided: some studies report low rates of suicidal attempts among immigrants, while other studies suggest higher rates as compared to native populations. ${ }^{32}$ This uncertainty is compatible with the non-conclusive indications about suicide found in our interviews with ExOr.

Mental health problems are also characteristic among LGBT people. Non-heterosexual populations have been found to experience a considerable prevalence of depressive episodes and high rates of anxiety, stress and suicide attempts. ${ }^{33}$ This has been associated, among other factors, with a unique challenge: deciding if, when, and how to reveal to others one's sexual orientation. ${ }^{22}$ Prevalence of mental health difficulties has been well documented for young adults. Early adulthood is a period marked by physical, mental, and emotional changes. It is also during this time of life that the onset of mental health disorders often occurs. $^{34}$

The other notable observation in our study relates to the tendency of ExOr to engage in risky behavior, manifested mainly by substance abuse and undertaking dangerous trips. This again parallels behaviors associated with immigrants, LGBT people and young adults. It is well accepted that the most characteristic aspect of health vulnerability of young adults, especially males, relates to risk taking. Violent death, either self-inflicted, or caused by homicide are prevalent at this age, ${ }^{35}$ and so is the tendency for reckless driving, excessive drinking and use of addictive drugs. ${ }^{36,37}$ Risky behavior manifested by substance abuse and alcohol consumption is also reported among certain immigrant groups, ${ }^{38,39}$ as well as among LGBT individuals. ${ }^{40}$ This suggests that transition processes may have similar effects on the be- 
havior of ExOr, immigrants, LGBT people and young adults.

The third motif revealed in this study is the effect of secularization of ExOr on sexual conduct. In this aspect one could also find resemblance to other populations in transition. Meta-analysis indicates that immigrant acculturation may promote multiple sexual partnerships, STIs and unsafe sex. ${ }^{41}$ Statistics also show that men who have sex with men have a higher risk of contracting an STI. ${ }^{42}$ In addition, sex related problems are quite prevalent among young adults. ${ }^{43,44}$ This could be related to the tendency to act carelessly among young adults (see above), as well as to the age-related desire for sexual experimentation, leading to unsafe sexual practices.

Another motif that appears to characterize populations in transition is the association between vulnerability and resilience. Some interviewees in our study stressed the role of resilience of ExOr in coping with their difficulties, suggesting that stress and resilience are not necessarily contradictory. Studies on immigrant populations, ${ }^{45}$ sexual minorities ${ }^{46}$ and college students ${ }^{47}$ suggest a continuum, or even partnership between vulnerability and resilience. Individuals in transition appears to mount responses that allow them to survive and even thrive despite stress. ${ }^{46}$ Resilience models suggest that individual characteristics and the encounter with stressful challenges can both enhance competence..$^{48}$ ExOr, as well as individuals who decided to immigrate, or to accept their sexual identities could be equipped with inherent resilience, which is then enhanced by the challenge of coping with the difficulties of transition. In these cases individual resilience could be seen as a part of community resilience.

Taken together, all these comparisons suggest a correlation in the health outcomes of different processes of transition: moving out from the Orthodox world, moving from adolescence to maturity, moving from one territory to another, and moving from denial of sexual orientation to its acceptance. It appears that all these transitions take a toll on mental health, sexual health and responsible behavior.

Limitations: In this study, we choose to address people that moved out from the Orthodox word before the age of 30 years. This is a well defined group in the Israeli society, with common social and ideological characteristic, and with notable representation in the general population. Our choice could have obscured the difference between the effects of young age and the effect of transitioning. The ideal way to solve this is to conduct a similar study with older ExOr. This however is not trivial. Moving out at older age occurs rather sporadically, those individuals are less accessible and the reasons for transition are probably more variable. In addition our study could suffer from a participation bias: the notable interest of our interviewees in health problems, and their willingness to open up can result from an inherent bias. One could claim that: individuals preoccupied with health and more secure about their status were more likely to take part in this study.

\section{Conclusions}

In summary, our findings regarding health concerns of ExOr suggest that this population is a potential health vulnerability group, and requires the attention of the health authorities. In addition, a comparison of our findings to findings regarding the health of immigrants, young adults and LGBT individuals draws the attention to a more generalized phenomenon. One could claim that the process of transition per-se can trigger health problems, and create vulnerability. We recommend that this consideration be added to the list of considerations that guide health professionals in identifying populations at risk and addressing their needs.

\section{References}

1. Lasser KE, Himmelstein DU, Woolhandler S. Access to care, health status, and health disparities in the United States and Canada: results of a cross-national population-based survey. Am J Public Health 2006;96:1300-7.

2. Frohlich KL, Potvin L. Transcending the known in public health practice: the inequality paradox: the population approach and vulnerable populations. Am J Public Health 2008;98:216-21.

3. Vanderbilt AA, Isringhausen KT, VanderWielen LM, et al. Health disparities among highly vulnerable populations in the United States: a call to action for medical and oral health care. Med Educ Online 2013;26:1-3.

4. Marmot M. Social determinants of health inequalities. Lancet 2005;365:1099-104.

5. Slaets JP. Vulnerability in the elderly: frailty. Med Clin North Am 2006;90:593-601.

6. Sen G, Ostlin P. Gender inequity in health: why it exists and how we can change it. Glob Public Health 2008;3:1-12.

7. Shi L, Stevens GD. Vulnerability and unmet health care needs. The influence of multiple risk factors. J Gen Intern Med 2005; 20:148-54.

8. Epel-Baron O, Kaplan G, Moran M. Perceived discrimination and health-related quality of life among Arabs and Jews in Israel: a population-based survey. BMC Public Health 2010;10:282.

9. Stolovy T, Levy YM, Doron A, Melamed Y. Culturally sensitive mental health care: a study of contemporary psychiatric treatment for ultra-orthodox Jews in Israel. Int J Soc Psychiatry 2013;59:819-23.

10. Isralowitz R, Reznik A. Russian speaking immigrants: drug use, infectious disease and related health behavior. J Immigr Minor Health 2014;16:1311-5.

11. Jaffe A, Giveon S, Wulffhart L, et al. Diabetes among Ethiopian immigrants to Israel: exploring the effects of migration and ethnicity on diabetes risk. PLoS One 2016;11: e0157354.

12. Putz U. Escape from Israel's ultra-Orthodox: the high price of religious defection. Der Spiegel 2010. Available from: http://www.spiegel.de/international/world/escape-from-israel-s-ultra-orthodox-the-high-price-of-religious-defectiona-678264.html

13. Biewener AK. Secularization in the Holy Land: Challenges for the State- Secularism and Nationalism in Israel. Int Relat Diplomacy 2018;4:718-28. 
14. Davidman L, Greil AL. Characters in search of a script: The exit narratives of formerly ultra-orthodox Jews. J Sci Stud Rel 2007;46:201-16.

15. Berger R. Challenges and coping strategies in leavening an ultra-Orthodox community. Qual Social Work 2015;14: 670-86

16. Hookway NS, Habibis D. Losing my religion: Managing identity in a post-Jehovah's Witness world. J Sociol 2015;51:843-56

17. Hinderaker A, O'Connor A. The long road out: Exit stories from the Church of Jesus Christ of Latter-day Saints. Commun Stud 2015;66:509-27.

18. Park MJ, Paul-Mulye T, Adams SH, et al. The health status of young adults in the United States. J Adolesc Health 2006;39:305-17.

19. Frankenthaler L. Dialogical deconversion; undercover infidelity understanding. J Rel Soc 2015;17:1-17.

20. Castañeda H, Holmes SM, Madrigal DS, et al. Immigration as a social determinant of health. Annu Rev Public Health 2015;18:375-92.

21. Fuller CB, Chang DF, Rubin LR. Sliding under the radar: Passing and power among sexual minorities. J LGBT Issues Counsel 2009;3:128-51.

22. Yarns BC, Abrams JM, Meeks TW, Sewell DD. The mental health of older LGBT adults. Curr Psychiatry Rep 2016; 18:1-11.

23. Giorgi A. The theory, practice, and evaluation of the phenomenological method as a qualitative research procedure. J Phenomenol 1997;28:235-60.

24. Rosmarin DH, Pargament KI, Flannelly KJ. Do spiritual struggles predict poorer physical/mental health among Jews? Int J Psychol Rel 2009;19:244-58.

25. Willson M, Daly M. Competitiveness, risk taking, and violence: the young male syndrome. Ethol Sociobiol 1985;6:59-73.

26. Glassne B, Berg B. How Jews avoid alcohol problems. Am Sociol Rev 1980;45:647-64.

27. Hurvitz-Prinz A. Sex and sexuality in formerly Ultra-Orthodox Jews: defining sexual health. Smiths ScholarWorks 2014. Available from: https://scholarworks.smith.edu/ theses/793

28. Lehmann D, Siebzehner B. Power, boundaries and institutions: Marriage in ultra-Orthodox Judaism. Eur J Sociol 2009;50:273-308.

29. Kirmayer LJ, Narasiah L, Munoz M, et al. Common mental health problems in immigrants and refugees: general approach in primary care. CMAJ 2011;183:E959-67.

30. Pernice R, Brook J. Refugees' and immigrants' mental health: Association of demographic and post-immigration factors. $\square$ J Social Psychol 1966;136:511-9.

31. Alegría M, Álvarez K, DiMarzio K. Immigration and mental health. Curr Epidemiol Rep 2017;4:145-55.

32. Forte A, Trobia F, Gualtieri F, et al. Suicide risk among im- migrants and ethnic minorities: a literature overview. Int J Environ Res Public Health 2018;15:E1438.

33. Chakraborty A, McManus S, Brugha TS, et al. Mental health of the non-heterosexual population of England. Br J Psychiatry 2011;198:143-8.

34. Kessler RC, Berglund P, Demler O, et al. Lifetime prevalence and age-of-onset distributions of DSM-IV disorders in the National Comorbidity Survey Replication. Arch Gen Psychiatry 2005;62:593-602.

35. CDC Violence and homicide among youth - Gateway to health. 2017. Available from: https://www.cdc.gov/healthcommunication/toolstemplates/entertainmented/tips/ViolenceYouth.html

36. Gibbons FX, Gerrard M. Predicting young adults' health risk behavior. J Personal Soc Psych 1995;69:505-17.

37. Donovan C, McEwan R. A review of the literature examining the relationship between alcohol use and HIV-related sexual risk-taking in young people. Addiction 1995; 90:319-28.

38. O'Hare T, Van Tran T. Substance abuse among Southeast Asians in the U.S: Implications for practice and research. Soc Work Health Care 1998;26:69-80.

39. Schiff M, Rahav G, Teichman M. Israel 2000: Immigration and gender differences in alcohol consumption. Am J Addict 2005;14:234-47.

40. Hughes TL, Eliason M. Substance use and abuse in lesbian, gay, bisexual and transgender populations. J Primary Prevent 2002;22:263-98.

41. Du H, Li X. Acculturation and HIV-related sexual behaviors among international migrants: a systematic review and meta-analysis. Health Psychol Rev 2015;9:103-22.

42. Centers for Disease Control and Prevention. CDC analysis provides new look at disproportionate impact of HIV and syphilis among U.S. gay and bisexual men. 2010. Available from: https://www.cdc.gov/stdconference/2010/msmpressrelease.pdf

43. Khan MR, Kaufman JS, Pence BW, et al. Depression transmitted sexually infection, and sexual risk behavior among young adults in the United States. Arch Pediatr Adolesc Med 2009; 163:644-52.

44. Newcomb ME, Clerkin EM, Mustanski B. Sensation seeking moderates the effects of alcohol and drug use prior to sex on sexual risk in young men who have sex with men AIDS. Behav 2011;15:565-75.

45. Bender DE, Castro D. Explaining the birth weight paradox: Latina immigrants' perceptions of resilience and risk. J Immigr Health 2000;2:155-73.

46. Meyer IH. Resilience in the study of minority stress and health of sexual and gender minorities. Psychol Sexual Orient Gender Diversity 2015;2:209-13.

47. Haddadi P, Besharat MA. Resilience, vulnerability and mental health. Procedia Soc Behav Sci 2010;5:639-42.

48. Garmezy N, Masten AS, Tellegen A. The study of stress and competence in children: a building block for developmental. Psychopathol Child Dev 1984;55:97-111. 